pons Varolii and medulla. The cerebral ganglia, pons, and medulla

appeared healthy on section.
OASE 18. Tubercular excavation of lung; empyema; abscess of brain OASE 18. Tubercular excavation of lung; empyema; abscess of brain
(left lenticular nucleus and centrum ovale).-A woman, aged 33 years. (left lenticular nucleus and centrum ovale).-A woman, aged 33 years.
Dr. Mitchell Bruce. B. H. May 6th to 23 rd, 1893 . Family history unimportant. Patient had left-sided pleurisy $22_{3}$ years previously. Since important. Patient had left-sided pleurisy $2 x^{3}$ years previously. Since then ill, and coughing up large quantities of purulent matter. Two months ago the empyema burst through left breast. She was operated on, on admission to Brompton, on May 12th, and a portion of the eighth
left rib, behind posterior axillary fold, was excised. The very day after operation much depressed and melancholic. (10 days before death.) May 16th: Temperature normal. Discharge smaller in quantity and slightly offensive Still melancholic. May 20th : Temperature 100.4. Mental condition unchanged. May 22nd: Temperature rising steadily
and is now $103.2^{\circ}$. During night coughed up much thick muco-purulent and is now $103 \cdot 2^{\circ}$. During night coughed up much thick muco-purulent material. May 23rd: Delirious during night. Unconscious this morning.
Right arm and leg quite flaccid. On pricking with a pin the left leg is Right arm and leg quite flaccid. On pricking with a pin the left leg is
drawn up, the right is not. Temperature $100.6^{\circ}$. The pulse was strong and full.

Post-mortem examination.-The body was much emaciated. Rigor mortis present every where. On the front of the left side of the chest there were the marks of four fistulous openings-two healed, one partly healed, and one open. Just below the left scapular angle there was an artificial opening, the margins of which were in a somewhat sloughy condition. The left pectoralis major muscle was greatly atrophied. Corresponding to the open fistula mentioned above there was some thickening of the periosteum, and the third rib cartilage was bare in

part of its length but not diseased.
Pleuræ. -The left pleural cavity was filled with tough adhesions at the upper part down to the second rib and costal cartilage. Below this was an empty cavity, extending down to the eighth rib behind, a portion of an empty cavity, extending down to the eighth rib behind, a portion of which had been removed. Below this there were again tough adhesions.
The right pleura was normal. There were firm pleuro-pericardial The right pleura was normal. There were firm pleuro-pericardial
adhesions on the left, none on the right side. The pericardium was adhesions on the left, none on the
normal. Heart normal (8 ounces).

Lungs.-The right lung was congested, but otherwise normal. The left lung was greatly collapsed below the middle of the upper lobe. The greater part of the upper lobe was occupied by a cavity having
smooth walls. In its neighbourhood there was a little old fibroid tubercle. A smaller cavity was found below this. In the lower lobe there was a little fibroid tubercle; no cavity. All abdominal organs normal, except that the spleen showed slight amyloid change.

Brain.-On removing the brain a great quantity of creamy pus was found beneath the pia mater over the pons and medulla covering the whole of the circle of Willis and running into the Sylvian fissure of each side. It seemed to proceed from near the foramen of Majendie. On incising the brain an abscess was found in the anterior part of the left lenticular nucleus and neighbouring white matter. The abscess contained much discoloured pus and was surrounded by hemorrhagic and inflamed brain substance. It had burst into the third ventricle thence into the fourth, and reached the surface of the brain at the was normal. mhere was but little meningitis. No tubercle of the brain was found.

CASE 19. Emryema (both sides) ; abscess (right temporo-sphenoidat $\left\{0^{\mathrm{k}} \hat{\mathrm{e}}\right)$.- - A man, aged 30 years. L.H. MIr. Barnard. The patient, a previously healthy man, had empyema first on the right May 14th empyema of left side had developed, and resection of rib was May 14 thed. Both sides were closing up satisfactorily when on June 10th he complained of severe headache and vomiting and drowsiness. Very rapidly paresis of the left side of face, left arm, and left leg developed.
On June 14th he could understand what was said to him if repeated On June 14th he could understand what was said to him if repeated several times. Incontinence of urine and fæces. Vomiting and much dilated; reacts to light. June 15th: Cerebral abscess right temporosphenoidal lobe was diagnosed. He was trephined; an abscess of the size of a walnut was found and drained. Patient did well for a week. The temperature then rose to $106^{\circ}$ and he died. Sto post-mortem examination was allowed. CASE 20. Bronchtectasis (cyitindrical); extensive thrombosis of veins
of neck.-A girl, aged 16 years. Dr. Hector Mackenzie. B.H. Nov. 25th, and had coughed much ever since. Larye quantities of sputa, occa sionally foul. Dyspnoea extreme. Temperature, $99^{\circ}$ on admission, in sionally foul. Dyspnoea extreme. Temperature, $99^{\circ}$ on admission, in early January, 1904, rose to $102^{\circ}$ in morning. Much clubbing of fingers tration of the lower lobe. On Jan. 2lst cedema set in, beginning in the frace and spreading to body and legs.

Post-mortem examination.-Pleuro.-Left pleur $a$ adherent all over the back. In front there were a few adhesions limiting the upper twothirds of the upper lobe over which a few ounces of serous fluid were found. Right pleurc adherent all over back and over upper part of the lung in front; over neither lung was the pleura much thickened.

Lungs. - Right: The upper lobe contained at its apex a cavity of the size of a Tangerine orange; it was of some standing, and though there was still some curdy material lining, the fibrous walls were beginning to form. A few grey tubercles were scattered in the remainder of this
lobe and in the lower lobe. Left: This showed a few scattered, deeply pigmented grey tubereles, but there was no other sign of tuberculous disease. On examining the bronchi very definite cylindrical bronchiectasis was found affecting the right and left lower lobes, and also th right upper lobe. It was most marked in the left lower lobe. The dilatation of the bronchi was very distinct, though nowhere extreme.

Heart, 7 ounces, natural. Abdominal organs, no abnormality.

Mediastinal glands. - The anterior and posterior groups were natural. The superior mediastinal group of glands was markedly enlarged and formed a definite mass in the superior mediastinum. One contained a fibro-caseous patch of the size of a pea. It is possible that the glands had by pressure on the veins produced thrombosis. In an adjoining gland a small caseous patch was also found. The right internal jugular vein from the skull to its junction with subclavian was filled with firm, ante-mortem clot of some standing. The right axillary vein and and also the left subclavian, axillary, brachial, median-basilic, and median cephalic veins were all filled with ante-mortem clot, but of more recent date than that on the right side. Other veins natural, including those in the legs, in spite of odema.

Brain.-Quite normal. No ante-mortem clot in any of sinuses of dura mater.
Historical ReCoRd and Literature.

The occurrence of abscess of the brain, secondary to disease of the lung, without general pyamia, with no foci of suppuration anywhere except in the brain, is a clinical entity which has only been fully recognised comparatively recently. "These cases of secondary abscess are among the most obscure, whether we regard their insidious origin or the primary disease which give rise to them" (Gull). In the earlier records the two conditions, pulmonary disease and cerebral abscess, are put down side by side as coincidences, without any suggestion of connexion between the two.

Bibliograpriy.-Powell (Richard): Some Cases Illustrative of Pathology of the Brain, Medical Transactions, published by the Royal College Pathological and Practical Researches on Diseases of the Brain and Spinal Cord, p. 95, 1828. Virchow : Brand-metastase von der Imange uf das Gehirn, Virchow's Archiv, vol. v., p. 275, 1853. Bamberger Uber Hirnkrankheiten, Verhandlungen der Physikalisch-Medizinischen Gesellschaft in Würzburg, vol. vi., pp. 216, 1855. Lebert: Ueber Gehirnabscesse, Virchow's Archiv, vol. x., pp. 78-109, 1856. Gull: On Abscess of the Brain, Guy's Hospital Reports, third series, vol. iil., pp. 261-310,
1857. Biermer: Ueber Bronchiectasis, Virchow's Handbuch der 1857. Biermer: Ueber Bronchiectasis, Virchow's Handbuch der Zur Pathologie des Hirnabscesses, Dissertation, Zürich, 1867. Gull and Sutton: Abscess of the Brain, Reynolds's System of Medicine, vol. ii., pp. 544-578, 1868. Meyer (Rudolf) : Berliner Klinische Woehenschrift, Nos. 42 and 43, 1868. Bottcher : Virchow's Jahresbericht, ii., 51,1869 ; and Petersburger Medicinische Zeitschrift, 1869. Pye-Smith: Pathological Society's Transactions, 1877. Petersson (O. V.): Idiopathic Cerebral Abscess, with Preceding Bronchitis, Schmidt's Jahrbuicher, Dilated Bronchi, Philadelphia Medical Times, vol. vii., p. 531, 1877. Reimer: Jahrbuch fïr Kinderheilkunde, xi., 1, pp. 50, 67, 1877, A Case of Abscess of Brain with Broncho-pneumonia in a Child, six years old. Huguenin: Acute und Chronische Entzïndungen des Gehirns und seiner Hüuenin: Acute und Chronische Entzundungen des Gehirns und seiner Häute, Ziemssen's Specielie Pathologie und Therapie, vol. xi., 1, 1878. Curschmann: Bronchiectasis and Abscesses in Brain, Berliner Klinische
Wochenschrift, 1878, p. 153 . Senator : Berliner Klinische Wochenschrift, 1879, p. 75. Hlava (Prague) : 1882. (Quoted by R. Naether, loc. cit.) Cayley (W.): A Case of Empyema with Cerebral Abscesses, THE LANCET, vol. i., 1884, p. 707. Naether (R.): Die Metastatischen Abscessen
nach Primären Lungenleiden, Deutsches Archiv für Klinische Medizin, vol. xxxiv., 1884, pp. 168-189. Havilland Hall (F. de) : A Caso of Empyema and Abscess of Brain, Clinical Society's Transactions, xvii., pp. 86-94, 1884. Bettelheim: Metastatische Hirnabscesse nach Empyem, Deutsches Archiv für Klinische Medizin, xxxv, p. 607, 1884. West (S.): Empyema ; Sudden Right Hemiplegia ; Abscess of TemporoSphenoidal Lobe, THE LANCET, vol. ii., 1885, p. 571 . Finlay (D. W.): Cerebral Abscess following an Empyema, THE LANCET, vol. i., 1886, p. Thomas's Hospital Reports, vol xvii., N.S. 1887. Gowers (Sir W. R.): The Diseases of the Brain. Drummond (D.) : Empyema with Abscess of Brain, THE LANCET, vol. ii., 1887, p. 7. Lacher: Fin Fall von Gehirnabscess in Auschluss an Bronchitis Putrida,
Minchener Medicinische Wochenschrift, 1887, No. 33, pas;

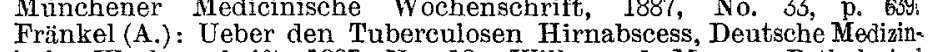
ische Wochenschrift, 1887, No. 18. Wilks and Moxon: Pathological ische Wochenschrift, 1887, No. 18. Wilks and Moxon : Pathological
Anatomy, 1889. Sainsbury $\left(\mathrm{H}_{\text {. }}\right)$ : Bronchiectasis followed by Absoess of Anatomy, 1889. Sainsbury (H.) : Bronchiectasis followed by Abseess of
Brain, The LANCET, vol. ii., 1889, p. 740. Fskridge and Clayton-Parkhill: Train, THE LANCET, vol. il., 1889, p. 740 . Fskridge and Clayton-Parkhil: Two Abscesses of the Brain caused by Septic Emboli Resulting from
Gunshot Wound of the Lung Inflicted Thirty-Two Years Before, New Gunshot Wound of the Lung Inflicted Thirty-Two Years Before, New
York Medical Journal, 1895, vol. lxii., p. 169. Benjamin (R.): Lungengangrän und Hirnabscess, Charité Annalen, 1903, pp. 180-191

\section{THE TEMPERATURE AS A GUIDE TO THE TREATMENT AND PROGNOSIS OF PHTHISIS.}

By S. VERE PEARSON, M.B. CANTAB., M.R.C.P. LOND., RESIDENT PHYSICIAN, MUNDESIEY SAYATORIUM.

I HAVE been struck in the past few years by the tendency there is to place too implicit faith in the effects of change of air, high altitude, and sea voyages in the treatment of phthisis, and to ignore a careful study of the symptoms. No doubt the tendency on the part of the sanatorium doctor is to over-emphasise the importance of rules based upon a study of symptoms, and perhaps to expect too much from enforcing an accurate regulation of the details of living under a hygienic régime, or at all events to desire to adopt this method of combating the disease in all cases and under every circumstance. But I feel sure it is more needful to draw attention to an opposite failing amongst those who. have had no special experience in the modern methods of treating phthisis. If a more thorough understanding of the value of a careful study of the symptoms of this disease, together with a greater precision in directing the management of the consumptive, were practised, the task of the sanatorium doctor would be much lightened, both in his curative efforts and in those directed towards a better education of the public. From personal experience in my own case I know the effects of high altitude or other climatio 
influences are not to be discredited in the treatment of phthisis. But I have become fully convinced that, while they have their place, this must be a very subsidiary one in the treatment of the great majority of consumptives, especially when activity of the disease first manifests itself by producing symptoms and leads to the discovery of the malady. There is no reason why treatment, based upon thorough and constant study of the symptoms, carefully supervised and precisely regulated, should not be combined with whatever advantages there are in the climatic influences of distant, much-vaunted places. But after visiting several of the more important health resorts renowned as attractive to the consumptive in Switzerland, North America, and the Riviera, I feel constrained to say that at a great many of these places, from one cause or another, often from causes over which the medical man has no control, too much is left to the climatic influences alone in the majority of cases, and much too little is done in the direction of that close and precise supervision and regulation of detail which is advocated by the doctors of the sanatoriums in Great Britain.

\section{Importance of Close Study of Symptoms.}

The modern treatment of consumption is based upon a knowledge of the powers of recovery naturally possessed by the body when placed under the best hygienic conditions, and requires for its maximum success a close study on the part of the physician of the symptoms of the disease and the recuperative powers of each individual patient. Amongst the symptoms the temperature is pre-eminently important Since the year 1893, when Dr. J. Kingston Fowler first drew particular attention to the importance of studying the various types of temperature met with in pulmonary tuberculosis, much attention has been paid to the temperature. More recently the writings of Dr. F. W. Burton-Fanning and Dr. K. Turban, not to mention the teachings of Dr. Otto Walther and his followers, have to some extent led medical men to realise the importance of a careful study of the temperature readings as a guide to treatment. It is recognised that (1) with a miliary tuberculosis it is usual to find a type of temperature continuous or inverse; (2) with an acute caseating tuberculosis a remittent or markedly intermittent type is found; (3) with a chronic fibroid tuberculosis constantly normal or subnormal is the rule; (4) while with a chronic fibro-caseous either a normal, subnormal, or a raised temperature is found, according to the stage and state of the disease.

In this paper my remarks about temperature as a guide to prognosis and treatment will refer more especially to cases of chronic fibro-caseous pulmonary tuberculosis.

\section{Method of Taking Temperature.}

In the first place, the choice of the method of taking the temperature calls for consideration. There can be no question that the reotal temperature is the most satisfactory. The alternative methods of mouth or urine temperatures or axillary readings are not so good. I have frequently found that the reading in the axilla or groin, even after leaving the thermometer in position for ten minutes or a quarter of an hour, has been considerably below $98 \cdot 4^{\circ} \mathrm{F}$. $\left(36 \cdot 9^{\circ} \mathrm{C}\right.$.), while the rectal reading at the same time has been at least $100^{\circ}\left(37 \cdot 8^{\circ} \mathrm{C}\right.$.) Mouth readings may be employed where any local condition contra-indicates the use of rectal temperatures. But, as Dr. Burton-Fanning has pointed out, if the oral temperature is used the thermometer must be kept in the mouth, with the mouth shut, for at least a quarter of an hour to get anything like reliable results. I believe in taking rectal temperatures whenever possible, however, for this method has the following advantages.

1. The actual temperature of the body is recorded. There can be no question that the roctal reading often gives a very different idea of the state of affairs from any other method of taking the temperature. For example, if the oral temperature is taken by anyone undergoing the open-air treatment during cold wintry weather a true record of the body temperature will seldom be obtained, even though he breathe through his nose.

2. The exeroise temperatere-i.e., the temperature taken immediately after some exercise-is often only properly estimated by this method. The oral temperature after exercise is frequently but little raised, while the rectal reading, taken at the same time, will show considerable elevation. Again, in some cases the temperature drops quickly after exercise, and if the patient has been breathing through the mouth the thermometer in the mouth will never record the height to which the temperature has been raised by the exercise.

3. It ondroates onset of relapse or oompiication. Rectal temperatures often indicate the onset of (a) relapse more readily and at an earlier date than any other method of recording the temperature; and $(b)$ the same may be said of the onset of a complication. I have known, for example, a patient who for a few days had the ambiguous warnings of the onset of meningitis, and no indication present of any complication in so far as oral temperatures were concerned. For a good many days oral readings showed no indication of any change from the previous satisfactory temperature readings, while rectal readings demonstrated during this period a very definite rise. It is of particular importance in respect to the early recognition of a relapse to remember that not infrequently the physical signs of the extension of the disease in the chest are only to be found after the symptoms of the set-back have subsided. Hence anything which helps towards an early recognition of a tendency to relapse is of the utmost importance in treatment, because with skill this inclination towards renewed activity or extension of the disease can be checked, and thereby often, I feel sure, a definite set-back warded off.

4. Often very slight disturbances of the body temperature are recorded only when rectal readings are taken.

The method of taking the temperature by urinating on to the thermometer is second only to the rectal method. It is usual for the temperature taken in the urine to be regularly about half a degree (F.) below the rectal readings, and it is fairly reliable. This method, therefore, is to be preferred under some circumstances, but it is not so generally reliable as the rectal method. Fisthetic reasons can easily be overcome in this matter of the method of taking the temperature. Most patients, as a matter of convenience, seem to prefer taking the temperature for from two to five minutes in the rectum, or by means of urinating on to the thermometer, to having to hold the thermometer in the mouth for 20 minutes.

\section{Times of Taking Temperature.}

The next point for consideration is the choice of the time for taking the temperature. For the thorough treatment of phthisis one must have frequent readings of the temperature. It is of no use, or rather it is of but little use, to take the temperature once a day-for example, in the evening. The height of the morning temperature should be known as well as the height of the evening temperature. It is important also to know the type of temperature curve. In choosing the times when the temperature should be taken and the conditions several points arise. In the first place, the reading first thing in the morning, and that some time about 6 P.M., are of special importance. In the second place, it is, in my estimation, preferable to take rest temperatures-i.e., to take the temperature when the patient has been at rest for a little time previously. The times $\mathbf{I}$ choose at the Mundesley Sanatorium are 7.45 A.M., 12 noon, 6.45 P.M., and 9.45 P.M. These temperatures are all taken after rest, with the exception of the mid-day one in the case of patients on exercise, when it is taken immediately after the morning exercise. Some authorities prefer to take two exercise temperatures in place of one, but my experience leads me to believe that the rest temperatures are the important ones. $\mathrm{My}$ rule is for patients to take their temperatures upon waking, before they get out of bed in the morning. I emphasise "before getting out of bed" because in many cases the mere effort of getting up, assuming the erect position, and washing sends the temperature up a few points. If, however, the patient is liable to wake early and begins, perhaps at 5 o'clock, to get anxious as to what his temperature is, I then tell him to take his temperature at a specified time-for example, 7.30 A.M. Otherwise he may be allowed to take his temperature upon waking. The second temperature in the day is taken immediately after the morning walk, or, if the patient is taking no exercise, it is taken at noon. I consider it as well to have one exercise temperature charted in the 24 hours. The third temperature is taken at the end of the evening rest hour, every patient being required to rest for one hour before the evening meal. The fourth temperature is taken after the patient has been in bed from 10 to 20 minutes. The interval between getting into bed and taking the temperature should always be the same. This is of 
importance, because while the patient is lying quietly in bed the temperature may be dropping several points. The length of the interval depends upon the habit of the patient in respect to how soon he falls to sleep after going to bed. It is important to have all these four observations at the beginning of the treatment at all events.

Interpretation of Temperature Readings.

Now as to the interpretation of the readings, my remarks will be based upon the rectal readings taken four times a day at the above suggested times. In the first place, it is most important to emphasise the fact that very minute variations from what may be considered normal readings in any individual case may be of the utmost importance in the treatment of consumption. Secondly, that the readings of the "rest" temperature in health are lower than is usually thought to be the case. Especially is it of importance to emphasise the fact that in health the reading should be $98^{\circ}\left(36.7^{\circ} \mathrm{C}\right.$.), or lower the first thing in the morning. There seems to be an all too widespread impression that the rectal temperature may be raised a degree above $98.4^{\circ}(36.9 \circ \mathrm{C}$.) without being of any serious pathological significance. If this is believed dire mistakes may be made in the treatment of consumption, for the pivot of successful treatment is to keep the patient at complete rest whenever any fever is present. Slight fever means activity of the disease. Activity of the disease indicates as much rest of the lungs as possible. If we have activity of a tuberculous lesion in any other part of the body-for example, the kneejoint-we rest the part until the activity has subsided. The lungs cannot be rested absolutely, but when active disease is present in them they should be rested as much as possible, and this necessitates complete rest in bed as a rule. The surest sign of activity about the lung lesion is the presence of some fever. Exactly what constitutes "some fever" is difficult to define, but the general rule which $I$ adopt is to consider activity to be present when the temperature readings are above $98^{\circ}\left(36.7^{\circ} \mathrm{C}.\right)$ in the morning or $99.40^{\circ}\left(37.45^{\circ} \mathrm{C}\right.$.) in the evening, unless have good grounds for believing the contrary. If both readings are above these points naturally more care must be taken than when only one is altered. If one is altered more importance must be attached to the elevation of the morning temperature than to an elevation of the evening temperature. The heightening of the evening temperature may be the indication of the slight remains of activity, but not so a raised morning temperature as a rule. Many patients with temperature readings so near the normal as $98^{\circ}\left(36 \cdot 7^{\circ} \mathrm{C}\right.$.) in the morning and $99.3^{\circ}\left(37.4^{\circ} \mathrm{C}\right.$.) in the evening will not make the best progress, or will sometimes make no good progress at all unless they be rested. The completeness of the rest must depend upon the nature of the case as judged by the temperature readings and other symptoms. If the prostration of the patient be great, and the temperature readings high with little tendency to improve, the rest should be complete, the patient not even being allowed to bath himself or walk to the closet. In fact, in some cases, as has recently been pointed out by Dr. A. Latham and Dr. M. S. Paterson, the quickest way to bring about a drop in the temperature is to treat the patient as if he were suffering from typhoid fever.

In treating consumption too much attention must not be paid to an isolated temperature reading. It is better to take a broad view of the readings for the previous few days in prescribing what a patient can or can not do. If an elevation of a few points in the temperature occur suddenly, and at the same time some other symptom of an adverse nature arise, then notice should be taken of the combination; if the elevation has no other adverse symptom accompanying it, then it can very often be disregarded. Of course, in any case a sudden high rise in temperature should always call for immediate attention. In relying upon the temperature readings it must not be lost sight of that, however much emphasis is laid upon their importance, the condition of the case must not be judged by them alone; also, that any rule of procedure for the treatment of patients cannot be made too hard and fast. In practice, however, I have found that the rules I formulate here need have but rare exceptions. In conjunction with the temperature the most important factors to which attention should be paid are : first, the aspect of the patient ; secondly, the body weight; and thirdly, the pulse.

Should the Patient Take His Onn Temperature?

I believe in teaching the patient how to take and chart his own temperature because then (1) it is easily possible to have all the necessary observations ; and (2) it is possible to make him capable of regulating his future doings scientifically. The weighing machine and thermometer intelligently used by a patient who has been well trained will often enable him to ward off relapse and to keep perfectly well. I do not approve of a patient, after he has got his disease arrested and left a sanatorium, taking his temperature regularly, nor of his being too reliant upon his own understandings of treatment. He must for some time keep in touch with a medical man. But the patient is sometimes unable to do this, or occasionally, I have found, unwilling to do so, because the only medical man available for him to consult seems to him to know less about the treatment of the disease from which he is suffering than he does himself. This is something of a reproach, though it is in the nature of the case that the patient should, perhaps by bitter experience, learn some details peculiar to his own case which it is difficult for his medical practitioner to pick up.

What is the Normal Temperature?

I have tried to bring out that there is no such thing as a normal temperature. There is an average temperature of health at a given time of day under given circumstances. This does not always seem to be sufficiently noticed, even by those who have expert knowledge of consumption, for in more than one recent publication dealing with the treatment of phthisis no details, or incomplete details, are given as to the exact time, method, and circumstance of the taking of the temperature. Precision in these matters is of the utmost importance in judging how to treat the patient, therefore their omission under such circumstances is to be regretted.

Since the early morning temperature of one patient may be $97^{\circ}\left(36 \cdot 1^{\circ} \mathrm{C}\right.$.) when he is in health and has perfectly quiescent disease, and that of another under similar circum. stances $98^{\circ}\left(36.7^{\circ} \mathrm{C}\right.$.), the proper temperature for any individual patient can only be discovered by experience. In this connexion it is well to mention that there is a tendency for the early morning temperature of the phthisical individual with quiescent or healed disease to be lower than that of a perfectly healthy person. Furthermore, I have upon occasion seen the rectal temperature take a lower position by several points after recovery from a relapse as com. pared with the temperature which was the rule after recovery from the primary trouble. Occasionally it is the morning temperature alone which is thus lower than before then the daily excursion between the highest and lowest readings is increased, while in other cases all the "rest" temperatures are lower. This is sometimes the case when the period of arrest has extended over years and is, I think, especially liable to occur if the fresh extension of the disease is either wide in area or intense in degree The converse also occurs; that is, after return to health has been established for a long period the temperature readings become less subnormal, or show a smaller excursion, or alter in both these respects. But it is not usual, in my experience, to see these latter changes occur quickly in the course of few weeks or even months. Hence I am not prepared to say to what extent they take place, because when a patient has made a good cure and keeps permanently well there is much more chance of losing sight of him after a few years, and in any case he will not bother himself with his temperature readings.

\section{The Temperature Curve.}

While there is a normal temperature for health in ang given individual, it must be remembered that this varies at different hours of the day, thus giving a normal curve o temperature. In health the lowest temperature in the 24 hours occurs between the hours of 1 A.M. and 4 A.M., while the highest daily reading occurs between the hours of 3 P.M. and 8 P.M. In the inverse type of temperature this normal curve is reversed, the temperature being highest in the early hours of the morning and lowest in the evening. But between these two extremes there are other types of curve, each of which has a special significance. Dr. N. D. Bardswell informs me that he collected some years ago many charts illustrating these departures from a normal type of curre; these he hopes to publish shortly. On the accompanying diagram are shown four types of temperature curve, which 1 call the normal, half-normal, half-inverse, and inverse. In the first the highest point is reached at 3 P.M., in the second at 9 P.M., in the third at 9 A.M., and in the fourth at 3 A.M. 
I have taken the 3 and 9 o'clock readings to simplify the diagrammatic representation. In studying a sufficiently large number of cases of consumption many will be found coinciding with, or approximating to, one or other of these types.

As it is seldom justifiable to bother the patient by asking him to take his temperature during the night a complete curve cannot usually be plotted. But when the temperature is taken four times a day according to the times suggested already it is not at all infrequent to find the following types: (1) the lowest temperature at 12 noon instead of first thing

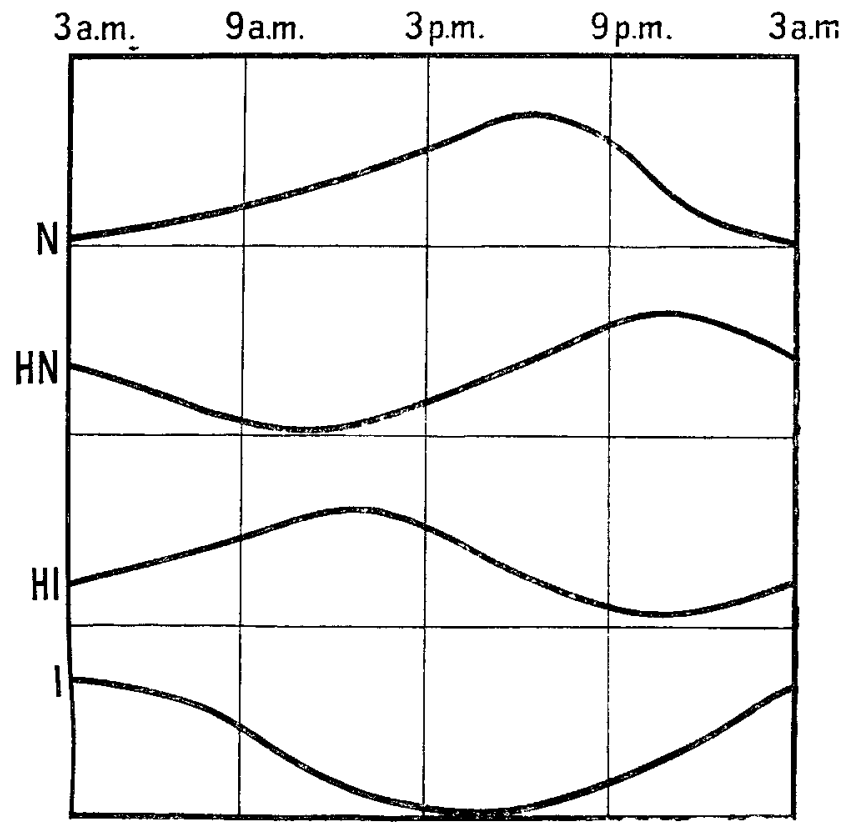

Chart representing Normal (N), Half-normal (HN), Half-inverse (BI), and Inverse (I) types of temperature curves respectively.

in the morning; (2) the highest temperature at 9.45 P.M. instead of 6.45 P.M.; and (3) an entirely erratic type of temperature, sometimes inverse, sometimes highest at noon, and sometimes lowest at noon, \&c. With regard to the relation of these types to prognosis, I generally look upon the last as the worst, while I look upon the second as better than the first. At one time it was considered that the inverse type of temperature indicated miliary tuberculosis. Sometimes it does, and while the inverse type usually demands a poor prognosis, with possibly little chance of permanent arrest of the disease, yet I have seen patients who showed this type of curve recover. Still more is it possible for the patient having the less severe abnormal type of curve to recover. With regard to treatment in connexion with the study of these types of curve, wherever the type of curve has departed from the normal, even though the elevations of temperature may not be at all severe, much more caution must be exercised, and particularly under such circumstances the advice "to make haste slowly" is applicable.

There is one more type of curve not infrequently met with, for a time at all events in some cases, and that is a temperature which shows little variation during any time of the 24 hours. (I do not refer here to the continuous fever, generally high or moderately high, of miliary tuberculosis.) Such patients, whose charts present something approaching a straight line, usually do badly if this peculiarity lasts long, even though the elevation may be but a few points above $98 \cdot 6^{\circ}$, and in such cases it is necessary to proceed with extra caution and not to be in a hurry to prescribe any exercise or exertion.

\section{Peculiarities in Women.}

I must next make mention of certain peculiarities of the temperature readings in women. It is usual for the temperature to be raised for some days before each monthly period, and this is physiological, within limits, as it occurs in normal healthy women. For example, a woman in perfect health whose usual rectal " rest" temperatures are $97 \cdot 9 \circ\left(36 \cdot 6^{\circ} \mathrm{C}\right.$.) A.M. and $98.6^{\circ}\left(37^{\circ}\right.$ C.) P.M. for seven days before menstruation begins may have average readings of $98.4 \circ$ $\left(36.9^{\circ}\right.$ C. $)$ A.M. and $99 \cdot 1^{\circ}\left(37 \cdot 3^{\circ}\right.$ C. $)$ P.M. The majority of women can be classified into three groups-viz., those who show this rise of temperature for $(a)$ a fortnight, $(b)$ ten days, or $(c)$ a week. Perhaps the commonest period for it to last is ten days; $I$ have seldom seen it markedly noticeable for longer than a fortnight. Amongst phthisical patients the extent of this rise is very commonly increased both in time and in degree. Not infrequently a shortening of the period of raised temperature is seen as a patient improves under sanatorium treatment. The rise is often gradual. Most frequently the temperature drops as soon as the flow of menses begins, but sometimes it does not drop until the flow has been established a day or two. Occasionally the temperature drops, generally within 24 hours, before the flow begins. The drop is not always complete at once, but is so more usually than not. If this feature of raised temperature is marked there is generally some exacerbation of the symptoms while the temperature is raised, and under such circumstances the resistance of the patient is undoubtedly lowered and she must be rested more. Sometimes the noticeable rise of temperature, and accompanying it feelings of lassitude and even of some malaise, is one of the last symptoms of ill-health to disappear, and one which may last very much longer than all others.

Rare and Ambiguous Cases.

There are occasionally to be met patients with indefinite symptoms and ambiguous signs in whom the temperature suggests that active tuberculosis is present. These cases show some elevation above the limits which I have said may be looked upon as the average temperature; thus one finds a patient with an early morning temperature about $98.4^{\circ}$ $\left(36.9^{\circ} \mathrm{C}\right.$.) or slightly above this, and with the evening temperature nearly always about $99 \cdot 5^{\circ}\left(37 \cdot 5^{\circ} \mathrm{C}\right.$.). As a rule, such temperatures fall under sanatorium treatment with plenty of rest, but in the cases that $I$ am now referring to the most careful treatment produces hardly any lowering of the temperatures. Under such cireumstances it is difficult to decide whether or not the patient has got tuberculosis, and, if tuberculosis is present, whether or not it is active; for, as I have indicated, these temperatures may occur when there are practically no abnormal physical signs and absence of sputum. Such raised temperatures may last for years, and during this period there are suspicions that the patient is not healthy. Perhaps while some of these individuals have no truly morbid condition, others have a tuberculosis of especially low virulence. It is in cases like these that a really reliable and harmless test is still wanted. Several exist, such as the tuberculin test, Calmette's ophthalmic, and von Pirquet's cutaneous reactions. But none of these can be considered both absolutely reliable and harmless. The patients belonging to this class seem to be nearly always of the female sex, and the condition may depend upon some uterine abnormality, for it is interesting to note in this connexion that pregnancy produces the same departures from the normal temperatures, and some of the patients I have had under my care have suffered from menstrual disturbances, in one case dependent upon the presence of a uterine fibroid.

\section{Regulation of Rest and Exercise.}

I have now to discuss in more detail the regulation of rest and exercise according to the readings of the temperature. Rest must be prescribed when fever is present. Fever should be considered to be present in any case of which the temperature readings are above $98^{\circ}\left(36^{\circ} \cdot 7^{\circ} \mathrm{C}\right.$. $)$ in the morning and $99 \cdot 3^{\circ}\left(37.4^{\circ} \mathrm{C}\right.$.) in the evening ; therefore rest such patients in bed until there are good grounds for believing that this does not constitute fever in the particular individual undergoing treatment. If in the case of a patient with slight fever strict rest in bed is insisted upon at a time when he is feeling comparatively well, it will be necessary to convince him, frequently, by persuasion or argument, that the course advocated is to his advantage. In order to do this the medical man must be convinced in his own mind that he is pursuing the right conrse, but at the risk of too much reiteration let me repeat the course I have already advocated -namely, that resting the patient when there is any fever is the only wise one to pursue. A difference of a few points of a degree on the wrong side of what is usually called normal should indicate rest, and often, if this course be not pursued, instead of the patient making an advance against the disease the disease will advance against the patient. Sometimes the patient will say that he always gets weak, or that he can never eat when kept in bed. Patients do not understand 
that weakness of the legs from lying in bed matters little in comparison to saving the lungs from rot. With regard to the appetite, generally patients do not lose weight or appetite in bed, but, on the other hand, especially when the debility is great from the continuance of fever, whether slight or marked, in my experience they gain flesh and their appetites increase. Often patients who have had lack of appetite or serious indigestion off and on for months, or perhaps years, get well, and get permanently the better of these symptoms when they are treated in the rational manner of resting them when fever, even in the slightest degree, is present.

\section{Persistently Raised Temperature.}

If the temperature is very persistently raised attention must be paid to the following points :-

1. Is there any other morbid condition preventing the temperature from dropping? By far the commonest cause of fever when pulmonary tuberculosis exists is the pulmonary tuberculosis. Even when tuberculosis of some other system is present it is much commoner for the lung disease to be that which is producing fever. Occasionally, however, slight persistent rise of temperature in a consumptive may be caused by a tuberculosis of some organ other than the lungs, and yet obvious symptoms and signs of this affection are absent; hence it may be overlooked. In this connexion care should be given not to overlook an early tuberculous affection in the genito-urinary tract.

2. Is the rest strict enough? Under this head, in the case of a patient being treated at home, very often talking to relatives and friends or the excitement of receiving visitors is at the bottom of the obstinacy in the fever. Letter writing sometimes, and even reading, has to be supervised and restricted.

3. Is the patient getting enough air? Sometimes it is found, as Dr. Burton-Fanning first pointed out, that the removal of a patient into freer air will materially help the reduction of fever.

4. Are you giving enough encouragement to the patient? A constant stream of encouragement does more than anything else, next to the cardinal principles of treatment, in helping the patient to make good progress. Very occasionally, for this reason, a relaxation of strict rest in bed may be necessary.

5. Is there anything on the patient's mind? It is astonishing what small matters will interfere with the progress of a patient, and sometimes a mental worry, which you do not suspect in the least because it is about a trivial matter, may be interfering with the progress.

6. Would a change do good? I have often found that if you can in any way give the patient a fresh start by changing the room or instituting some slight addition or modification of the treatment, a period of more rapid and surer progress towards recovery is inaugurated. I believe that the removal to fresher air, such as from a room to a chalet or open-air shelter for both night and day, or the starting of a course of tuberculin, acts partly in this way. The patient feels something more is being done, and if he is persuaded to have a more abounding faith the added modification in his régime will encourage him and tell in his favour. In this connexion it should be mentioned that it is frequently well to recommend complete change of environment. In the case of sanatorium patients a move to another sanatorium or a visit home may be advisable.

7. Has the time arrived when exercise might be tried ? Very occasionally a cautious beginning in this direction aids the reduction of the fever. But experience and experiment show that the error of starting too soon is far commoner than the converse. In lieu of exercise sometimes a little gentle general massage is useful.

8. Is the thermometer at fault?

9. Is the patient practising deceit?

\section{Starting Exercises.}

When a point or two of improvement shows itself on the readings of $98 \cdot 2^{\circ}\left(36 \cdot 8^{\circ}\right.$ C. $)$ A. M. and $99 \cdot 4^{\circ}\left(37 \cdot 45^{\circ}\right.$ C. ) P.M. , then the patient may cautiously begin exercise. When exercise is started for a tuberculous patient the golden rule is to make haste slowly. Let the increase in the amount of exercise be almost imperceptible from week to week in a case where fever has lasted any length of time. In a case where there has been very little fever let more exercise be given gradually, so that from day to day the patient is hardly aware that he has been given more, but from week to week, or fortnight to fortnight, he is able to appreciate considerable increase. Never increase the amount of exercise on a rising temperature. In prescribing exercise never depend on one isolated observation or feature of the temperatures, but on the height and general oharacteristic of the curve for some days previously. If from the additional guides to be got from studying the general appearance and gain in weight it cannot be decided whether or not to advance the exercise, try - and see the result. For example, I had a patient a year or two ago whose temperature was persistently a few points above $98 \cdot 6^{\circ}$ (37 ${ }^{\circ} \mathrm{C}$.). He had been a very severe case of consumption. Even after a great many months complete rest, during which 3 stones were gained in weight and there was a corresponding improvement in the patient's general condition, the temperature, though seldom high, still remained a few points up. At length I tried the effects of exercise, but for a long time whenever I gave the patient more to do the temperature got worse, and the patient's state and symptoms deteriorated. The indica. tion clearly was to continue the rest. In another patient, and perhaps especially in one who does not show much daily variations in temperature, but where the temperature is slightly though not seriously raised, exercise sometimes has a beneficial effect when first started. Exercise may act in two ways. The mere fact that the patient is prescribed the advance of starting exercise cheers him up, and by this means sometimes favours his progress. But more important than this, as a rule, is the influence which exercise undoubtedly has by means of auto-inoculation. The effect of regular exercise properly prescribed is frequently shown not only by the improved general tone and vigour of the patient and by his lesions showing indications of better and more rapid healing, but also by lower and more regular temperatures.

\section{Two Illustrative Cases.}

As an illustration of how much exercise to give, and how important it is to pay attention to other signs as well as to the temperature readings, I might take the case of two female patients who were under my care a short time ago. Both temperature readings for several days at this time were exactly the same-viz., $98^{\circ}\left(36 \cdot 7^{\circ}\right.$ C. $)$ A.M. and $99 \cdot 5^{\circ}$ $\left(37 \cdot 5^{\circ}\right.$ C.) P.M. Yet one patient was taking walking exer. cise to the extent of five or six miles daily, while the other was confined strictly to bed and was allowed but a limited amount of talking and letter writing. The former had been under treatment three or four months, had never had any other than comparatively slight signs and symptoms, and these had largely cleared up. Her general condition was excellent, while at the time I am speaking of the patient was within a week of her monthly period, before which, for rather longer than a week, the temperature was always raised three or four points. The other patient had gained weight, but was still suffering from frequent, rather troublesome cough, with occasional retching, some loss of appetite, and indigestion. Her general aspect was not first-rate ; there was a good deal of general debility, and constantly a small quantity of flaky muco-purulent expectoration containing tubercle bacilli. The temperature during two months had shown but slight improvement, and though a trifle better for a few days after the menstrual flow had been established a day or two, its best was seldom appreciably lower than the above readings of $98^{\circ}$ A.M. and $99 \cdot 50^{\circ}$ P.M.

\section{Indications of Too Much Exercise.}

If a patient is being over-exercised there are several guides from the temperature readings which can help to indicate this. (a) The exercise temperature may rise too high. The height to which the exercise temperature goes depends upon the state and the idiosyncrasy of the patient as well as upon the distance walked or the nature of the exercise if other than walking, and the pace at which the exercise is taken. It may be influenced also by meteorological conditions and by the amount of clothing the patient wears. Under ordinary circumstances a patient in good condition taking a proper walk at not too fast a pace, or doing light gardening work, or something of a similar nature, does not increase his temperature above $100 \cdot 4^{\circ}$ (380 C.). (b) The exercise tem. perature may not drop quickly enough. When the disease is quite quiescent and the patient doing satisfactorily, it will be found that the temperature after exercise has dropped to $98.6^{\circ}$ within three-quarters of an hour of the end of the exercise. A temperature going up after the cessation of 
exercise is an adverse sign; one going down quickly is good. In normal man the temperature after exercise drops to near $98.6^{\circ}$ in about 20 minutes. (o) The evening temperature may begin to rise. Either the 6 o'clock temperature or the 9 o'clock temperature may be higher than it has previously been, and this may indicate that the patient has been taking too much exercise. Usually " $a$ " will be noticed before " $b$," and " $b$ " before " $a$." ( $d$ ) Lastly, the morning temperature may begin to rise, but this seldom occurs without some indication from the temperature readings as indicated under the heads $a, b$, or $c$. In considering this point, however, the state of quiescence of disease must be taken into account, because at the time when the disease has only just lost its activity slight variations from what I consider the proper temperature readings will occur of one sort or another. For example, during this stage the morning temperature may be a few points up as a result of over-exercising the patient without the other indications having occurred.

\section{Instability and Lack of Elasticuty of the Temperature.}

In the treatment of phthisis it is well to remember that until the disease is perfectly quiescent there are two characteristics of the temperature.

1. Instability.- Slight causes may produce marked results in raising the temperature. The results of physical exertion have been referred to already. Exercise properly used is a most valuable therapeutic agent. But the abuse of exercise is more potent for evil in consumption than anything else. More patients step briskly towards their graves from over. exerting themselves physically than from any other cause. It is important to recognise also that mental excitement may cause marked rise of temperature at a time when the disease has not yet become quiescent. Comparatively slight grades of over-exertion, either in the way of physical exercise or mental excitement, may keep a temperature persistently raised. So, too, may a secondary morbid condition of apparently no grave significance, such as pyorrhoa alveolaris. Again, slight causes may give rise for a short time to distinct, and sometimes even quite alarming, temporary febrile disturbances. As illustrations of this I might give a number of examples. Each of the following causes has distinctly produced a noticeable rise in the temperature of patients I have had under my care during the past year: (a) constipation; (b) diarrhca ; (c) indigestion; $(d)$ receipt of a worrying letter; $(e)$ love sickness; $(T)$ a game of cards (g) hot weather; and, in another case, a thunderstorm. Again, occasionally it is found during the early stages of treatment that the exertion of digesting a meal is sufficient to send the temperature up several points.

2. Lack of elasticity. - By this is meant a lack of speedy return to a normal level when the temperature has become raised, whether from a slight cause or from noticeable exertion.

When patients are constantly taking and charting their own temperatures it is expedient every now and then to take measures to prevent over-anxiety as to the readings. Sometimes individuals get temperatures on their nerves, and this interferes with good progress. It is usually possible to laugh them out of their condition, or by admonitions and reassurances to get them out of it. If this cannot be done, then it is much better to do away with all thermometers and charts, for a time at all events. If for any reason temperature readings are of particular importance, the doctor or nurse should always be present to read the temperature at the prescribed times. Or, if this is not convenient, as may be so when frequent rectal readings are required, it is possible to procure clinical thermometers made in two pieces in such a way that the temperature can only be read when the stem is screwed in to a part with the graduated markings upon it, and this can be left for the doctor or nurse to do.

\section{Objects and Resuits of Treatment.}

In treating consumption according to the rules which I have indicated above it is always well to remember the objects we have in view. If a long-standing advanced chronic case of pulmonary tuberculosis is being dealt with it may be useless to aim so high as should be done in a case more favourable for obtaining permanent arrest of the disease. It is improbable that perfect quiescence of the disease can be obtained in certain advanced chronic cases, especially if the proper rational treatment has been given a good trial and has failed to arrest the disease. But I hold strongly to the opinion that the opportunity of taking that chance which prolonged rest under suitable conditions will give to many advanced cases, apparently hopeless of cure, should be given. Furthermore, many cases of consumption, apparently hopeless because of the acuteness of the malady, respond eventually in a marvellous way if patience, perseverance, and belief in the efficacy of absolute rest are exercised. But the rest must be very complete when the temperature is high, and must by every endeavour be continued so long as there is the slightest trace of fever. Regardless of all rules and regulations, many a case of consumption will reach a period of quiescence and sometimes arrest of the disease, but the chances of these going on to a permanent arrest-i.e., to a cure-are not nearly so great if the patient has not learnt how to ward off the recurrence of further activity. This he can only do by learning the rules and régime necessary for him to observe in order to bring about quiescence and arrest of the disease.

Mundesley, Norfolk.

\section{CLINICAL AND PATHOLOGICAL ASPECTS OF A SERIES OF "DOUBTFUL" TUMOURS OF THE BREAST.}

\section{By T. BONHÔTE HENDERSON, M.A., M.B., B.CH. OxON., F.R.C.S. ENG.,}

SURGICAI REGISTRAR, THE CANCER HOSPITAL, BROMPTON.

IT has for long been recognised that the text-book description of the physical signs of mammary cancer is totally inadequate from the practical point of view, and is moreover actually dangerous in lulling the practitioner into a false security in any tumour of the breast which does not present the classical characteristics. Briefly these are, of course, a "stony hardness," dimpling of skin, retraction of nipple, enlarged and hard axillary glands, and perhaps fixation of the growth to the parietes or fascia beneath it. When these signs are developed not only can anyone make a diagnosis, but perhaps the golden moment for successful operation has passed. Tumours of the breast may be roughly divided into three classes for clinical purposes, the undoubtedly malignant, the doubtful, and the innocent, and these grades in actual practice pass insensibly into one another. It is the doubtful cases to which this paper calls attention, and it will be recognised how great is the diversity of clinical characteristics to be found in this class, that no amount of text-book education is of any assistance in certain cases, and further that certain cases cannot be successfully diagnosed by anyone. A careful perusal of these cases submitted below will make it unnecessary for me to emphasise my conviction that every operable tumour or swelling of the breast should be submitted to operation. My own experi. ence has taught me that the more "doubtful" cases I see the more chary am I of offering a definite opinion-Experientia non docet. In the course of the past two and a half years I have seen and personally recorded the notes of 257 cases of breast tumours. Out of these I find that 23 , all of which have been submitted to operation, have given exceptional difficulty in diagnosis ; in fact, I have preserved an open mind until the microscopical section has been made and the pathological report has been returned. If in these 23 cases I have made, before operation, any provisional diagnosis, it has generally been disagreeably reversed by the microscope. I do not mean to infer that the other cases have been correctly diagnosed, but only that they did not at the time puzzle one as these other cases have done. For instance, in a case of " recurrent carcinoma" the nodule of recurrence proved to be an ordinary needle embedded in inflammatory tissue, with no explanation as to how it got there!

It has been considered advisable to divide these doubtful cases into three groups-those which microscopically proved to be malignant, those which proved to be innocent, and those which, even after microscopical examination, still remained doubtful.

Class I.-Doubtful Cases which proved to be Malignant.

CASE 1.-The patient was 44 years of age and unmarried. The father and mother had died from phthisis. Tumour of left breast (? duration), glands of left side of neck and left axilla of eight months' duration, after influenza Breast tumour 